Cahiers $d u$ MONDE RUSSE

\section{Cahiers du monde russe}

Russie - Empire russe - Union soviétique et États indépendants

$58 / 4 \mid 2017$

Varia

\title{
Michael Kunichika, " Our Native Antiquity »: Archeology and Aesthetics in the Culture of Russian Modernism
}

\section{Ioulia Podoroga}

\section{(2) OpenEdition}

\section{Édition électronique}

URL : http://journals.openedition.org/monderusse/10199

DOI : 10.4000/monderusse.10199

ISSN : $1777-5388$

Éditeur

Éditions de l'EHESS

\section{Édition imprimée}

Date de publication : 1 octobre 2017

Pagination : 757-760

ISBN : 978-2-7132-2698-4

ISSN : $1252-6576$

\section{Référence électronique}

loulia Podoroga, «Michael Kunichika, «Our Native Antiquity »: Archeology and Aesthetics in the Culture of Russian Modernism », Cahiers du monde russe [En ligne], 58/4 | 2017, mis en ligne le 01 octobre 2017, consulté le 06 janvier 2021. URL : http://journals.openedition.org/monderusse/10199 DOI : https://doi.org/10.4000/monderusse.10199 
Michael KUNICHIKA

"Our Native Antiquity "

Archeology and Aesthetics in the Culture of Russian Modernism

Boston : Academic Studies Press, 2015, 344 p.

L'ouvrage de Michael Kunichika aborde une problématique au cœur de la préoccupation du modernisme russe : l'engouement pour un passé archaïque authentiquement « russe » (historiquement valable ou mythologique, « inventé ») que les 
poètes et artistes de cette époque cherchent à doter d'une valeur esthétique particulière et dans lequel ils trouvent des ressources pour leur propre activité créative. Dans cette perspective, l'auteur se donne pour tâche d'analyser comment les deux artéfacts principaux issus de l' " antiquité natale » russe, la statuaire de pierre (kamennaja baba) et les tertres funéraires (kurgan), attributs incontournables du paysage de steppe russe, sont appropriés par la pensée moderniste et, dans quelle mesure, ils ont pu contribuer à façonner la poétique moderniste en tant que telle. Cet ouvrage érudit et bien documenté se situe à la croisée de plusieurs disciplines : slavistique, études littéraires, histoire de l'art et de l'archéologie, anthropologie.

L'auteur commence par une riche préhistoire des images littéraires de la steppe dans la culture russe au XIX ${ }^{\mathrm{e}}$ siècle, de Puškin à Čehov, en passant par Tolstoj. De vastes espaces troublants dont l'horizontalité est brisée par ces collines artificielles de terre surmontées de stèles (babas de pierre : «baba», probablement d'origine turque, signifiant " père », ou «balbal » - « ancêtre ») dont l'aspect brut, grossier est d'autant plus menaçant qu'on ignore tout sur leur fonction. S'agit-il d'un rite funéraire et des offrandes faites à Dieu (puisqu'ils tiennent des coupelles) ? Ou bien sont-ce des statues de la fertilité (de par leurs formes plutôt amples et l'apparence souvent féminine), ou encore de sinistres idoles, condamnées pour avoir désobéi aux Dieux ? On ignore également tout ou presque de leur provenance. Même si l'on attribue les nécropoles les plus anciennes aux Scythes, les steppes parcourues dans tous les sens par divers peuples (Grecs, Polovcy, Mongols, Cosaques, Slaves, etc.) ont dû recueillir des vestiges de multiples cultures.

Michael Kunichika se propose d'abord de restituer tout un spectre de significations que le mot kurgan recouvre dans la langue russe. Ce terme est employé, sur le plan historique, pour désigner d'anciens tombeaux (chez Puškin dans son Chant d'Oleg le Sage, ou ceux des héros de l'Iliade, dans la traduction russe). L'usage romantique du kurgan en fait un attribut des espaces mornes et infinis, typiquement russes. Mais dans l'imaginaire russe, les kurgan sont aussi des lieux de mémoire. Chez Tolstoj notamment, comme Malahov Kurgan dans ses Récits de Sébastopol ou dans Guerre et Paix, lorsque Pierre choisit de monter sur un kurgan pour surplomber la plaine de Borodino. C'est donc un sujet privilégié de la « topographie poétique russe » (p. 84) et, selon l'auteur, ces connotations témoignent de la «flexibilité symbolique remarquable » (p. 89) du mot.

L'intérêt littéraire pour les kurgan s'accroît à la suite d'importantes découvertes archéologiques. À partir du milieu du XIX ${ }^{\mathrm{e}}$ siècle, les fouilles des kurgan sont de plus en plus nombreuses et concluantes. Ainsi d'après l'influent historien et archéologue Ivan Zabelin, les kurgan sont des berceaux de l'histoire nationale (p. 90), et sans en étudier le passé, sans se l'approprier, la Russie ne peut devenir une nation « civilisée ».

De façon analogue, les babas de pierre se présentent comme source d'un imaginaire spécifique pour les poètes modernistes russes. L'auteur renvoie, entre autres, à Ivan Bunin (1908), Aleksej Remizov (1910), Sergej Gorodeckij (1911) qui consacrent des récits et longs poèmes aux babas de pierre. C'est avant tout l'œuvre de Velimir Hlebnikov qui jouit d'une place centrale dans l'élaboration d'une poétique archaïque russe, et la $b a b a$ est son personnage de prédilection, à tel point 
qu'une $b a b a$ a été choisie pour orner sa tombe. Dans ses poèmes, la $b a b a$ revêt un paradigme de métamorphoses temporelles, un « opérateur » qui fait passer d'un temps cyclique païen vers un temps historique contemporain (temps des guerres, comme la Guerre de 1914, par exemple), et vice versa.

Dans l'avant-garde picturale russe, la fortune des babas est encore plus spectaculaire. Considérées d'abord comme barbares, donc dénuées de valeur esthétique en comparaison avec l'idéal classique de l'art grec, les babas de pierre ont progressivement changé de statut, jusqu'à devenir un paradigme pour un art cubiste national. Loin d'être «barbares » dans le sens dépréciatif du mot, ces statues sont qualifiées de "primitives », c'est-à-dire dégageant une beauté simple et pure. Natal'ja Gončarova, figure de proue de ce courant, « interprète polémiquement la statuaire en termes de cubisme » (p. 164), en fondant ainsi un style primitiviste russe.

La dernière partie de l'ouvrage porte sur les années 1920 qui marquent une transformation radicale d'interprétation quant à la valeur et la place des artéfacts de la steppe dans la nouvelle «culture bolchevique». Naturellement, ces artéfacts font désormais partie d'un passé bourgeois et sont donc à rejeter nécessairement. Or, puisqu'il s'agit de vestiges chargés affectivement et symboliquement, leur rejet ne peut être que dramatique et c'est bien ce dramatisme que mettent en scène les romans de Boris Pil'njak : L'Année nue (1922) et La Volga se jette dans la Caspienne (1930). Dans le premier de ces deux romans, les kurgan donnent lieu à des fouilles archéologiques qui agissent à la fois comme une façon de désacraliser ces espaces, de les décharger de leur passé et comme une manière de faire revivre, sans doute pour une dernière fois, des rites païens pratiqués par la population du village voisin (qui, de façon inattendue, fait irruption dans le roman). Avec la recrudescence de la guerre civile en toile de fond, ce site archéologique assume la signification du kurgan comme lieu de souffrance et de mort.

Lors de son examen du second roman de Pil'njak, l'auteur introduit le concept de « site de déformation », afin de comprendre comment l'industrialisation forcée agit en lieu et place de l'archéologie : découverte et destruction en même temps. Une autre question s'impose toutefois : quelle est la valeur de l'antiquité (ces babas qui se font exhumer par les héros archéologues du roman) pour le monde à venir? Le passé semble persister, malgré tout, à travers de multiples trouvailles archéologiques. Comment peut-on alors restaurer ce passé, l'adapter au présent et le faire servir pour le futur?

Cette analyse approfondie de la symbolique de la steppe est complétée par une étude du film La 11 e année (1928) de Dziga Vertov. L'auteur s'interroge sur l'intérêt que porte le cinéaste à la figure du guerrier (prétendument scythe), dont le squelette est retrouvé près d'un vaste chantier soviétique Dnieprostroi (construction d'une centrale hydro-électrique du Dniepr), que Vertov est en train de filmer pour son documentaire célébrant les dix ans du pouvoir soviétique. Quatre-vingts kurgan datant de l'âge de pierre et de l'âge de bronze sont découverts sur ce site. L'invincibilité de la steppe russe étroitement associée à l'art guerrier scythe relève de la mythologie poétique symboliste qui s'est formée à la fin du $\mathrm{XIX}^{\mathrm{e}}$ siècle autour de la figure du Scythe et des liens de parenté présumés entre les anciens Scythes 
et les Russes. Vertov réactive cette mythologie, non pas pour opposer le passé archaïque au présent, mais pour les faire s'interpénétrer. La force soviétique émergente tient sa puissance du passé scythe comme d'une force élémentaire qu'il s'agit pour elle de dépasser et d'intégrer à une nouvelle conscience culturelle célébrant les capacités de vainqueur propres à l'ouvrier soviétique.

L'identité russe, l'histoire et la création d'une tradition nationale font partie de ces questions « éternelles » qui se posent à chaque génération de Russes depuis au moins deux siècles. Le moderniste prérévolutionnaire et l'avant-garde révolutionnaire s'y prennent différemment. Le mérite de l'ouvrage est de revenir sur cette problématique controversée à la lumière d'artéfacts archéologiques concrets, afin de suivre au plus près leur traitement particulier chez chaque poète, écrivain ou artiste, autant de façons de s'approprier son passé et de contribuer à la constitution d'une identité nationale.

Ioulia Podoroga

CERCEC et Eur'Orbem 